\title{
Prognostic and predictive value of plasma testosterone levels in patients receiving first-line chemotherapy for metastatic castrate-resistant prostate cancer
}

\author{
A G de Liaño ${ }^{1}$, O Reig ${ }^{2}$, B Mellado ${ }^{2}$, C Martin ${ }^{1}$, E U Rull ${ }^{1}$ and J P Maroto ${ }^{\star 1}$ \\ ${ }^{1}$ Medical Oncology and Biochemistry Departments, Hospital de la Santa Creu i Sant Pau, Mas Casanovas s/n, 08025 Barcelona, \\ Spain and ${ }^{2}$ Medical Oncology Department, Hospital Clinic, Carrer Villarroel 170, 08036 Barcelona, Spain
}

Background: Biomarkers for metastatic castration-resistant prostatic cancer (mCRPC) are an unmet medical need.

Methods: The prognostic and predictive value for survival and response to salvage hormonal therapy (SHT) of baseline testosterone level (TL) was analysed in a cohort of $101 \mathrm{mCRPC}$ patients participating in 9 non-hormonal first-line chemotherapy phase II-III trials. Inclusion criteria in all trials required a TL of $<50 \mathrm{ng} \mathrm{dl}^{-1}$.

Results: Median age: 70 years; visceral metastases: 19.8\%; median prostate-specific antigen (PSA): $50.7 \mathrm{ng} \mathrm{ml}{ }^{-1}$; median TL: $11.5 \mathrm{ng} \mathrm{dl}^{-1}$. Median overall survival (OS; 24.5 months) was significantly longer if baseline $\mathrm{TL}$ was above (High $\left.T L ; n=52\right)$ than under (Low TL; $n=49$ ) the TL median value (32.7 vs 22.4 months, respectively; $P=0.0162$, hazard ratio $(H R)=0.6)$. The presence of anaemia was an unfavourable prognostic factor (median OS: 20.6 vs 28.4 months; $P=0.0025, H R=1.88$ (C195\%: 1.01-3.48)). Patients presenting both anaemia and low testosterone had a worse outcome compared to those with one or none of them (median OS: 17.9 vs 22.4 vs 38.1 months; $P=0.0024)$. High vs Low TL was associated with PSA response rate (55.6\% vs $21.7 \%$ ) in 41 patients receiving SHT.

Conclusion: Testosterone level under castration range was a prognostic factor for survival mCRPC patients. The PSA response to SHT differed depending on TLs. Testosterone levels might help in treatment decision.

Castrate state has been defined as a testosterone plasma level from 20 to $50 \mathrm{ng} \mathrm{dl}^{-1}$. Today, it is accepted by consensus that target testosterone level (TL) for androgen-deprivation therapy involving the use of luteinising hormone-releasing hormone (LH-RH) agonists must be $<50 \mathrm{ng} \mathrm{dl}^{-1}\left(1.7 \mathrm{nmoll}^{-1}\right)$. Docetaxel has been considered as the gold standard treatment for patients with metastatic prostate cancer progressing under castrate levels of testosterone. In the recent years, we have contemplated the arrival of new therapeutic options, either chemotherapy (CT) with cabazitaxel or hormone therapy with enzalutamide or abiraterone. Enzalutamide (Scher et al, 2012) and abiraterone (de Bono et al, 2011) have proven efficacy for both patients with metastatic castration-resistant prostatic cancer (mCRPC) progressing after docetaxel and in first-line therapy for asymptomatic patients or for those with low symptoms (Ryan et al, 2013a; Prevail trial, 2013). Cabazitaxel provided a benefit in survival for those patients progressing after docetaxelbased CT (de Bono et al, 2010). Although survival has improved, necessity of optimisation of therapy together with some small preliminary reports of cross-resistance between abiraterone and enzalutamide (Loriot et al, 2013; Noonan et al, 2013) or abiraterone and docetaxel (Mezynski et al, 2012) have raised the necessity of biomarkers to help the right choice of therapy for each individual patient. 
In patients receiving LH-RH agonist or surgical castration, testosterone can still be detected in plasma. Baseline TL, although under the definition of castration, has been suggested to be both prognostic for survival (Morote et al, 2007) and predictive of response to subsequent hormonal manoeuvres (Hashimoto et al, 2011).

Looking to new prognostic and predictive values for survival in mCRPC, we analysed the role of baseline TL and other potential factors (such as haemoglobin) in a cohort of patients with mCRPC. In addition, we analysed the probability of response to salvage hormone therapy (SHT) upon progression to first-line treatment.

\section{PATIENTS AND METHODS}

Study population. To have a homogeneous cohort, only patients with histologically confirmed metastatic prostate cancer (mCRPC) participating from August 2006 until September 2012 in trials in two single institutions in Spain were included in this analysis. Patients were recruited from nine different non-hormonal first-line CT phase II-III trials. Follow-up was until death or last contact date.

All trials uniformly required, as inclusion criteria, a surgical or medical castration and confirmatory castrate levels of testosterone (TL $<50 \mathrm{ng} \mathrm{dl}^{-1}$ ). Testosterone level was determined at the screening blood analysis, using an automated immunoassay (Testosterone, ARCHITECT system I 2000 [B7K730], Abbott, Longford, Ireland; or Testosterone II, Elecsys; Roche, Mannheim, Germany) within 1 month before starting the first-line CT treatment. The protocol for collection and measurement of TLs was performed according to the manufacturer's instructions (Testosterone I Architect 2006 system package insert; Abbott Diagnostics Division Lisnamuck, Longford Co. Longford, Ireland; B7K730; or Testosterone II Immunoassay Elecsys 2010 System Product Information; Roche Diagnostics GmbH, Mannheim, Germany). All patients gave their informed consent in written for blood testing. Disease progression was defined as documented osseous or soft-tissue metastatic progression (under Response Evaluation Criteria in Solid Tumours (RECIST) v1.1 (Eisenhauer et al, 2009), or prostate-specific antigen (PSA) progression according to Prostate Cancer Clinical Trials working Group II criteria (PCWGII) (Scher et al, 2008).

Overall survival (OS) was calculated as the time from the date of study inclusion to death. Disease-free progression (DFP) was the time from the date of study inclusion to date of progression. Post$\mathrm{CT}$ progression was defined either as an objective progression according to the RECIST or as a PSA progression. The PSA progression was defined as three consecutive increases in serum
PSA from the nadir value of either at least $25 \%$ for men without PSA response ( $\geqslant 50 \%$ confirmed PSA decline from baseline) or at least a $50 \%$ increase from nadir for all others. The PSA response was defined as partial if $\geqslant 30 \%$ reduction. Time from progression to death (TPD) was defined as the time from progression after first-line therapy to death.

Patients who received hormonal treatment after first-line progression were included in a sub-analysis to measure their PSA response to SHT and post-progression survival.

Statistical analysis. Survival times (OS, DFS, and TPD) were analysed using a Kaplan-Meier model. For a statistical purpose, patients were stratified into two groups according to their baseline TL. Those patients with baseline TL below median value were classified as 'Low TL' and as 'High TL' if baseline TL was above median TL value. Prostate-specific antigen was included in the model as a continuous variable as well as categorical (median value). Other factors analysed were anaemia (defined as $\mathrm{Hb}$ values $<12.0 \mathrm{~g} \mathrm{dl}^{-1}$ ), Gleason score $(>7 v s \leqslant 7)$, serum level of alkaline phosphatase $\left(>131 \mathrm{IUl}^{-1}\right), \mathrm{LDH}$ (high $v s$ normal), age $(\geqslant 65 v s$ $<65)$, the presence or absence of visceral metastases, hepatic metastases or dyslipidemia, and the use of statins.

Univariate and multivariate analyses were performed. Variables that achieved statistical significance in the univariate analysis were included in a stepwise COX regression model for multivariate analysis. All analyses were performed using SAS Version 9.3. (SAS Institute Inc., SAS Campus Drive, Cary, NC, USA)

The guidelines for the reporting of tumour marker studies (REMARK) were followed to analyse and present data on studied biomarkers (McShane et al, 2005).

\section{RESULTS}

Patient population. One hundred and one patients with histologically confirmed mCRPC who were treated with first-line CT, in any of the non-hormonal first-line CT phase II-III trials were included in the analysis. The great majority of patients received a docetaxel-based regimen $(n=68)$ as first-line CT. Table 1 summarises the trials where patients were included in a timely basis.

Median age of patients was 70.0 years (range: 41.0-89.0) and $19.8 \%(n=20)$ patients had visceral metastases. The median PSA was $50.7 \mathrm{ng} \mathrm{ml}^{-1}$ (range: 0.04-1284.0), the median haemoglobin was $13.1 \mathrm{~g} \mathrm{dl}^{-1}$ (range: 9.3-156.0), and the median alkaline phosphatase was $163 \mathrm{Ul}^{-1}$ (range: 39.0-1159.0).

Before development of $\mathrm{mCPRC}$, all subjects received at least two hormonal treatments. These included an LH-RH analogue either

Table 1. First-line clinical trials for metastatic castrate-resistant prostate cancer selected

\begin{tabular}{|c|c|c|c|c|}
\hline Trial & Phase & Experimental arm & Control arm & Total $(n, \%)$ \\
\hline $20050103^{a}$ (NCT00321620) & 3 & Denosumab + Placebo $\pm \mathrm{CT}$ & Zoledronic + Placebo \pm CT & $10(9.9)$ \\
\hline CA180-227 (NCT00744497) & 3 & Dasatinib + Docetaxel & Placebo + Docetaxel & $10(9.9)$ \\
\hline CA184-095 (NCT01057810) & 3 & Ipilimumab & Placebo & $2(1.9)$ \\
\hline CEPO906A2229 (NCT00411528) & 2 & Patupilone & Docetaxel 75 & $11(10.9)$ \\
\hline FIRSTANA (NCT01308567) & 3 & Cabazitaxel 25 or 20 & Docetaxel 75 & $12(11.8)$ \\
\hline VENICE (NCT00519285) & 3 & Aflibercept & Placebo + Docetaxel & $15(14.9)$ \\
\hline E7389-G000-204 (NCT00278993) & 2 & Eribulin & None & $14(13.9)$ \\
\hline H8Z-MC-JACR (NCT00642018) & 2 & LY2181308 + Docetaxel 75 & Docetaxel 75 & $10(9.9)$ \\
\hline SINERGY (NCT01188187) & 3 & OGX-011+Docetaxel & Docetaxel & $17(16.8)$ \\
\hline
\end{tabular}


alone or in combination with an antiandrogen. When an LH-RH was administered alone at first instance, then an antiandrogen was added at progression. If the combination was used as the first approach, then the second hormonal manoeuvre was the withdrawal of the antiandrogen. Three patients received surgical castration instead of an LH-RH analogue. Four patients (4.0\%) received more than two hormonal manoeuvres before first-line CT was introduced. These treatments corresponded to ketoconazol in three cases and diethylstilbestrol in one patient. Of these four, only one received salvage hormonal treatment after CT failure.

The median TL was $11.5 \mathrm{ng} \mathrm{dl}^{-1}$ (range: from undetectable to 49.0 ), with $19 \%$ of the patients having an undetectable level and $85 \%$ of the patients having less than $20 \mathrm{ng} \mathrm{dl}^{-1}$ of testosterone in plasma. Figure 1 depicts the distribution of serum baseline TLs. Baseline TL was above the TL median value in 52 patients (High TL group) and under the TL median value in 49 patients (Low TL group). No significant differences were observed in baseline characteristics between groups (Table 2).

Median TL was $7.9 \mathrm{ng} \mathrm{dl}^{-1}$ in patients who were using statins at the time of inclusion $(n=18)$, while median TL was $11.5 \mathrm{ng} \mathrm{dl}^{-1}$ in those patients without statins $(n=78)$. No significant correlation $(P=0.3418)$ was noted between the use of statins in patients and baseline TLs value.

Efficacy and survival analyses. At the moment of analysis (June 2013), 90 out of 101 patients had failed to first-line CT and 57 out of 101 patients had died. Median follow-up of patients was 20.6 months (range: 8.3-29.8). Median OS was 24.5 months (CI95\%: 21.8-31.7).

Kaplan-Meier analysis stratified by TLs showed a median DFS higher in those patients with High TL than with Low TL (5.7 vs 4.9 months, respectively; $P=0.001)$. Median OS was also longer in those patients with High TL compared with Low TL (32.7 vs 22.4 months, respectively, $P=0.0162$ ) (Figures $2 \mathrm{a}$ and $\mathrm{b}$ ). When stratified by haemoglobin levels, OS was 28.4 vs 20.6 months (No anaemia $v s$ Yes, respectively; $P=0.0025$, Figure $3 \mathrm{a}$ ), and OS was 35.9 vs 22.8 months when age was analysed $(<65$ vs $\geqslant 65$ years old; $P=0.0259$; Figure $3 b)$.

The univariate analysis of OS demonstrated TLs (High TL vs Low TL, hazard ratio (HR): 0.5 ; CI95\%: $0.3-0.9 ; P=0.018$ ), the presence of anaemia (Yes vs No, HR: 2.4; CI95\%: 1.3-4.4; $P=0.0024)$, baseline PSA before CT $\left(<51\right.$ vs $\geqslant 51 \mathrm{ng} \mathrm{ml}^{-1}$, HR: 0.5 ; CI95\%: $0.3-0.8 ; P=0.0074)$, and age ( $<65$ vs $\geqslant 65$, HR: 0.5 ; CI95\%: $0.3-0.9 ; P=0.0294)$ to be statistically significant. Other potential prognostic factors for survival analysed did not

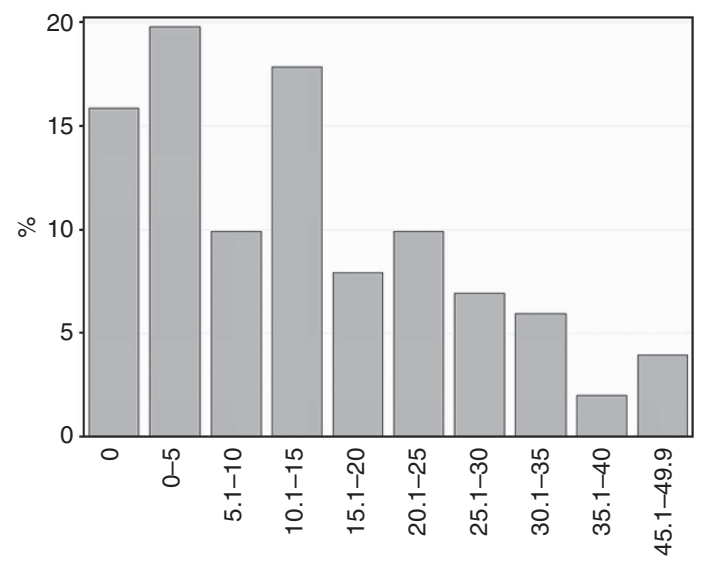

Baseline testosterone $\mathrm{ng} \mathrm{dl}^{-1}$

Patients with TL values under the assay sensitivity were assigned a 0 TL value.

Figure 1. Distribution of serum androgen levels at baseline. show statistically significant differences: Gleason $(>7$ vs $\leqslant 7$ : median OS: 22.8 vs 30.3 months; HR: 1.2; CI95\%: 0.7-2.2; $P=0.4661$ ), the presence of visceral metastasis (Yes $v s$ No: median OS: 16.5 vs 26.2 months; HR: 1.3; CI95\%: 0.7-2.4; $P=0.4634$ ), liver metastases (Yes vs No: median OS: 16.5 vs 26.2 months; HR: 2.0; CI95\%: $0.8-4.7 ; P=0.1206$ ), LDH (high $v s$ normal: median OS: 19.9 vs 26.8 months; HR 1.5; CI95\%: $0.8-2.8 ; P=0.2387$ ), serum alkaline phosphatase levels $\left(\geqslant 131\right.$ vs $<131 \mathrm{IUl}^{-1}$ : median OS: 24.1 vs 26.8 months; HR: 1.3; CI95\%: $0.7-2.2 ; \quad P=0.4249$ ), dyslipidemia (Yes vs No: median OS: 22.4 vs 26.8 months; HR: 1.1 ; CI95\%: $0.7-1.9 ; P=0.6564$ ), or the use of statins (Yes $v s$ No: 22.4 vs 28.4 months; HR: 1.3; CI95\%: 0.7-2.4; $P=0.4975)$.

The multivariate analysis of OS showed TLs (High vs Low testosterone) to be in the limit of significance (HR: 0.6; CI95\%: $0.4-1.0 ; P=0.0689$ ) and anaemia (Yes $v s$ No) to be a significant factor (HR: 1.9; CI95\%: 1.0-3.5; $P=0.046$ ). A significant interaction between both variables was demonstrated, showing that High TL was a protective factor when there was not anaemia (HR: 0.5; CI95\%: $0.3-0.8)$. Age $(<65 v s \geqslant 65)$ was not a statistically significant factor in the multivariate analysis (HR: 0.6; CI95\%: $0.3-1.1 ; P=0.1075$ ). Baseline PSA showed a strong correlation with anaemia $(P=0.0046)$ and was not included in the multivariate analysis.

Since levels of haemoglobin and testosterone were significant or marginal factors for OS, we classified patients into three groups: (patients presenting two risk factors (anaemia and Low TL), one risk factor, or without risk factors), and a Kaplan-Meier model was used to analyse the OS. Patients presenting two factors (anaemia and Low TL) had a worse outcome compared to those with one or none of them (median OS: 17.9 vs 22.4 vs 38.1 months, respectively; $P=0.0024$ ) (Figure 4 ).

Post-progression survival or TPD was 16.4 months (CI95\%: 12.5-25.4) in the Low LT group of patients vs 23.7 months (CI95\%: 16.5-35.8) in the High LT group $(P=0.0456)$ (Figure 5).

In 95 out of the 101 patients, PSA response was evaluated. The percentage of responders by PSA to first-line CT was similar in both groups (High LT $57.7 \%(n=30)$ vs Low LT $61.2 \%(n=30)$ ). There was not a statistically significant association between PSA response and baseline TL $(P=0.1381)$. The application of a logistic model provided similar results (Wald Chi-square $P=0.3468$ ). Also, PSA response rate was not associated with baseline TL in 68 of the 72 patients that received a docetaxel regimen as first-line CT (High TL $70.6 \%(n=24)$ vs Low TL $67.7 \%(n=23) ; P=0.5827)$. The PSA response was not assessed in four patients receiving a docetaxel-based CT regimen. Thus, baseline TLs were not predictive of PSA response to first-line docetaxel.

Response to SHT and post-progression survival. After first-line CT failure, 41 out of 101 (40.6\%) patients received salvage hormonal treatment. As described before, all of these patients had received at least two hormonal manoeuvres before first-line CT. Treatments received consisted of diethylstilbestrol $(n=12,29 \%)$, ketoconazol $(n=11,27 \%)$, abiraterone $(n=9,22 \%)$, bicalutamide or high-dose bicalutamide $(n=7,17 \%)$, cyproterone acetate $(n=1$, $2 \%)$, and enzalutamide $(n=1,2 \%)$.

The PSA response to SHT was observed in $36.6 \%(n=15)$ of the patients, while $56.1 \%(n=23)$ of the patients were non-responders (SD and PD). Response data were not available in three patients. Response was observed in $21.7 \%(n=5)$ of the Low TL patients $v s$ $55.6 \%(n=10)$ in the High TL group. A majority $(73.9 \% ; n=17)$ of the Low TL patients were non-responders, compared with $33.3 \%$ $(n=6)$ in the High TL patients $(P=0.0196)$.

\section{DISCUSSION}

In spite of castrate levels of testosterone, all patients with metastatic prostate cancer receiving treatment with either medical 


\begin{tabular}{|c|c|c|c|c|}
\hline & Low TL & High TL & Total & $P$-value \\
\hline No. of patients & 49 & 52 & 101 & \\
\hline \multicolumn{5}{|l|}{ Age (years) } \\
\hline $\begin{array}{l}\text { Median (IQR) } \\
\text { Min, Max }\end{array}$ & $\begin{array}{c}71.0(64.0,75.0) \\
52.0,85.0\end{array}$ & $\begin{array}{c}69.0(64.0,75.0) \\
41.0,89.0\end{array}$ & $\begin{array}{c}70.0(64.0,75.0) \\
41.0,89.0\end{array}$ & 0.5862 \\
\hline \multicolumn{5}{|c|}{ Visceral metastases, $n$ (\%) } \\
\hline $\begin{array}{l}\text { Yes } \\
\text { No } \\
\text { Missing data }\end{array}$ & $\begin{array}{c}11(22.5) \\
38(77.6) \\
0(0.0)\end{array}$ & $\begin{array}{c}13(25.0) \\
39(75.0) \\
0(0.0)\end{array}$ & $\begin{array}{c}24(23.8) \\
79(78.2) \\
0(0.0)\end{array}$ & 0.7634 \\
\hline \multicolumn{5}{|c|}{ Hepatic metastases, n (\%) } \\
\hline $\begin{array}{l}\text { Yes } \\
\text { No } \\
\text { Missing data }\end{array}$ & $\begin{array}{r}6(12.2) \\
43(87.8) \\
0(0.0)\end{array}$ & $\begin{array}{c}6(11.5) \\
46(88.5) \\
0(0.0)\end{array}$ & $\begin{array}{c}12(11.9) \\
89(88.1) \\
0(0.0)\end{array}$ & 0.9127 \\
\hline \multicolumn{5}{|c|}{ Gleason score } \\
\hline $\begin{array}{l}\leqslant 7 \\
>7 \\
\text { Missing data }\end{array}$ & $\begin{array}{r}18(36.7) \\
25(51.0) \\
6(12.2)\end{array}$ & $\begin{array}{c}21(40.4) \\
28(53.9) \\
3(5.8)\end{array}$ & $\begin{array}{c}39(38.6) \\
53(52.5) \\
9(8.9)\end{array}$ & 1.0000 \\
\hline \multicolumn{5}{|c|}{ Haemoglobin value $\left(\mathrm{gl}^{-1}\right)$} \\
\hline $\begin{array}{l}\text { Median (IQR) } \\
\text { Min, Max }\end{array}$ & $\begin{array}{c}132.0(120.0,138.0) \\
98.0,156.0\end{array}$ & $\begin{array}{c}130.5(123.0,138.0) \\
93.0,153.0\end{array}$ & $\begin{array}{c}131.0(122.0,138.0) \\
93.0,156.0\end{array}$ & 0.5397 \\
\hline \multicolumn{5}{|c|}{ Alkaline phosphatase $\left(\mathrm{IUI}^{-1}\right)$} \\
\hline $\begin{array}{l}\text { Median (IQR) } \\
\text { Min, Max }\end{array}$ & $\begin{array}{c}179.0(120.0,291.0) \\
58.0,1159.0\end{array}$ & $\begin{array}{c}129.0(77.0,245.5) \\
39.0,790.0\end{array}$ & $\begin{array}{c}163.0(87.0,260.0) \\
39.0,1159.0\end{array}$ & 0.0531 \\
\hline \multicolumn{5}{|l|}{ PSA (ng ml ${ }^{-1}$ ) } \\
\hline $\begin{array}{l}\text { Median (IQR) } \\
\text { Min, Max }\end{array}$ & $\begin{array}{c}59.5(19.5,202.0) \\
2.4,1284.0\end{array}$ & $\begin{array}{c}50.2(17.6,124.5) \\
0.04,514.0\end{array}$ & $\begin{array}{c}50.7(18.9,138.0) \\
0.04,1284.0\end{array}$ & 0.3138 \\
\hline \multicolumn{5}{|l|}{ LDH } \\
\hline $\begin{array}{l}\text { Normal } \\
\text { High } \\
\text { Missing data }\end{array}$ & $\begin{array}{l}27(55.1) \\
12(24.5) \\
10(20.4)\end{array}$ & $\begin{array}{r}34(65.4) \\
11(21.2) \\
7(13.5)\end{array}$ & $\begin{array}{l}61(60.4) \\
23(22.8) \\
17(16.8)\end{array}$ & 0.6254 \\
\hline
\end{tabular}

or surgical castration will finally progress, entering the so-called castrate-resistant state. Although it was thought that these patients were truly progressing independent of the activity of the androgen receptor (AR), today it is well known that the AR is still activated in most patients. In fact, the activity of docetaxel, the present standard of care in MCRPC, can partly be explained through its activity over the AR, blocking the process of internalisation (Darshan et al, 2011). The knowledge that the activation of the AR permits prostate cancer to escape from the castrate levels of testosterone has conducted to the development of new therapies centred in reducing plasma and intratumoral TLs (Attard et al, 2008). Though adrenal and intratumoral de novo androgen synthesis contributes to disease progression (Locke et al, 2008; Montgomery et al, 2008), the relationship between serum androgens and intratumoral androgens remains poorly understood. In addition, an escape of testosterone from testis may occur in some patients (Morote et al, 2007), with prognostic implications (Perachino et al, 2010). A potential role of residual plasma androgens has been studied. Peripheral baseline androstenedione was predictive of response to ketoconazol in patients with mCRPC (Small et al, 2004). Abiraterone acetate, an inhibitor of CYP17-20 hydroxylase, provides a further reduction in the level of plasma testosterone that correlates with PSA response in patients progressing after ketoconazol-based therapy. The final proof of concept for abiraterone came through data from a positive phase III trial in $\mathrm{mCRPC}$ patients progressing after docetaxel-based CT (de Bono et al, 2011), and from a small translational study where abiraterone was more effective for tumours with a tumour nuclear AR expression, coupled with cytoplasmic CYP17 expression (Efstathiou et al, 2012). Ryan et al (2013b) found that baseline serum androgen (testosterone, androstenedione, and dehydroepiandrosterone sulfate (DHEAS) levels were a validated biomarker that was prognostic for survival in the patients treated with abiraterone after docetaxel failure in the phase III trial. The relationship of TL with PSA response by first or salvage therapies was not analysed in their study.

Our hypothesis states that plasma TL might reflect the activity of the AR. Against the use of TLs, is the fact that they may be affected by diet and circadian conditions, not well accounted for in our study; and that there are other androgens in plasma, not only testosterone. Although, to date, no models exist that account for total androgen load, as opposed to the measurement of the level of an individual hormone (e.g., testosterone), this could be an 
A Disease-free survival by testosterone level

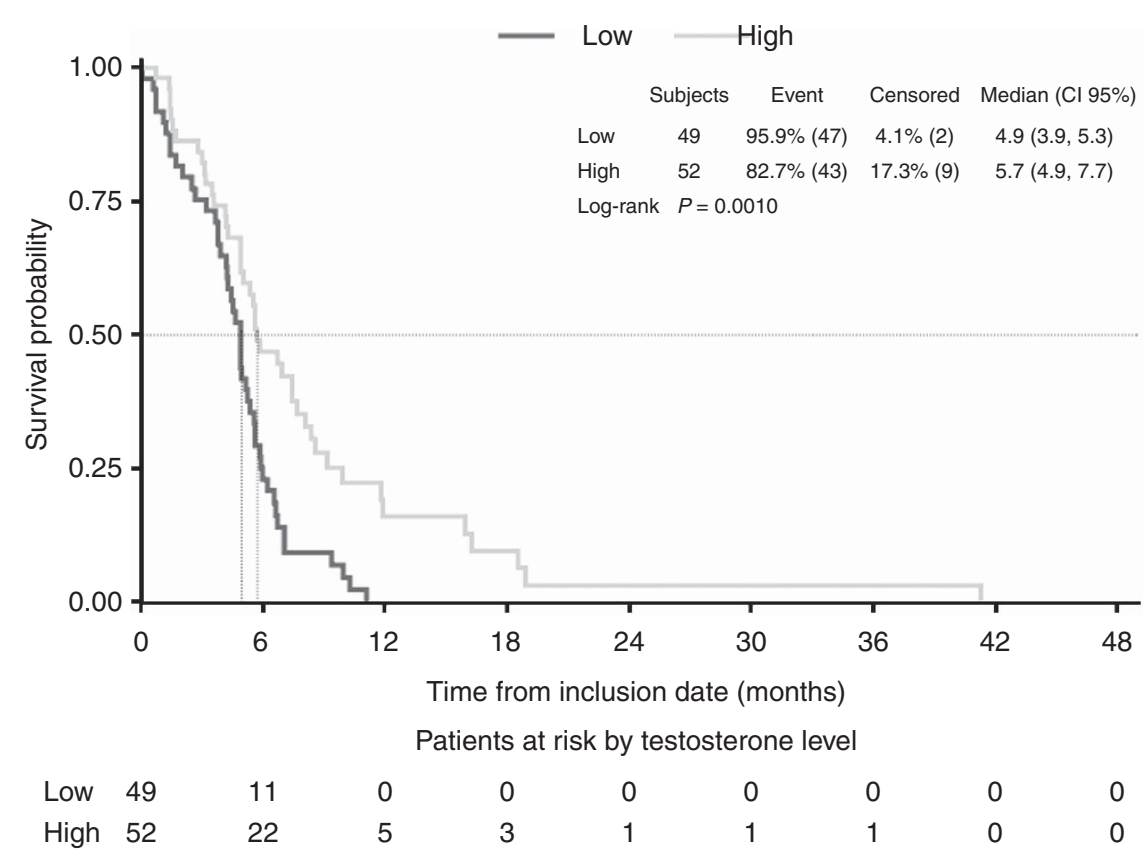

B

Overall survival by testosterone level

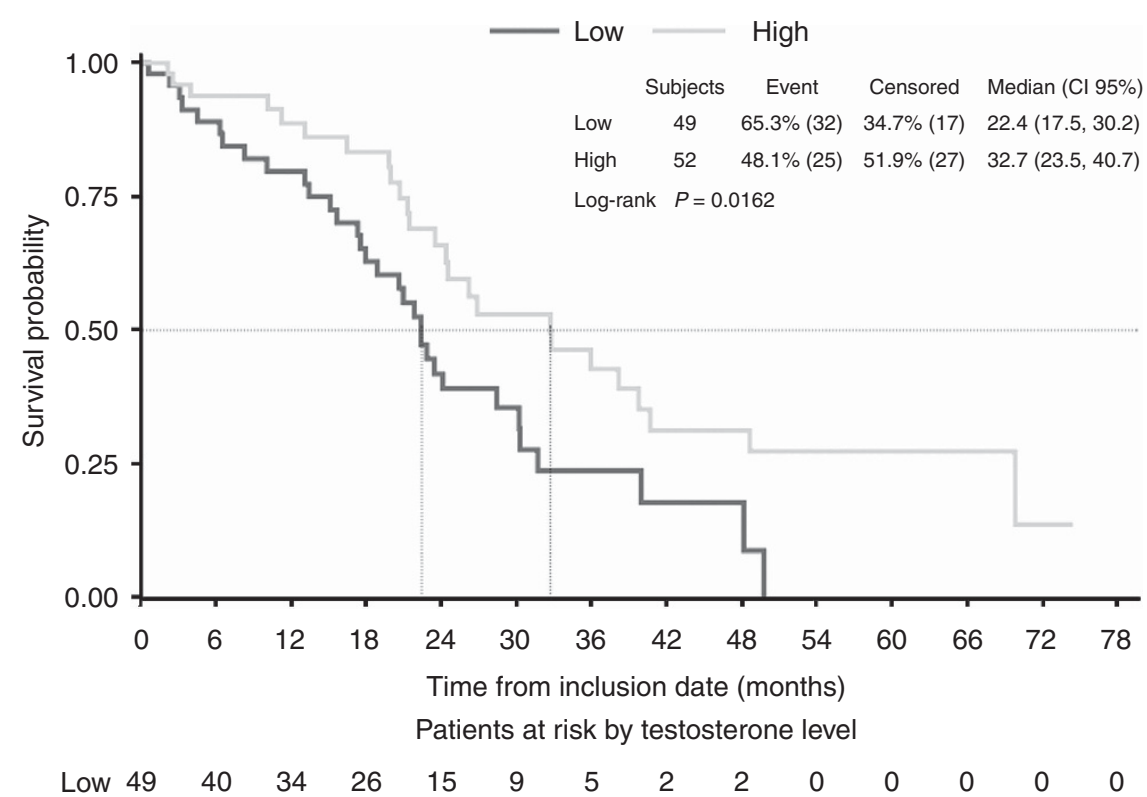

Figure 2. Disease-free survival (A) and overall survival (B) according to testosterone baseline levels.

interesting point of further investigation, and maybe, a more accurate tool than a single hormone level.

In our study, we demonstrated that testosterone baseline levels under castration were a prognostic factor for survival before firstline CT. Several caveats should be considered when interpreting these data, including the fact that these analyses were exploratory, with no attempt to correct for multiplicity. Testosterone was measured using commercial assays, thus, a definitive cutoff point could not be established. Novel and more precise ultrasensitive techniques are nowadays available, although not implemented on the daily practice. Since androgen synthesis depends on cholesterol, TL may be reduced by the use of statins. Although in our analysis the difference observed was not statistically significant, the figures are not comparable due to the small proportion of patients that were using statins compared with those who were not. Interestingly, patients using statins had a worse OS (22.4 vs 28.4 months), although this result was not statistically significant $(P=0.4964)$ and again, the interpretation is limited by the small size of the population that used these drugs. Although we could hypothesise that reducing androgen levels with statins may drive to a lower baseline testosterone plasma levels and this could impact on patients outcome, this seems very unlikely, and patients using statins could have a worse OS due to other reasons such as cardiovascular associated comorbidities, although these was not analysed. Finally, low TL might be a manifestation of a patient 
A Overall survival (strata $\mathrm{Hb})$

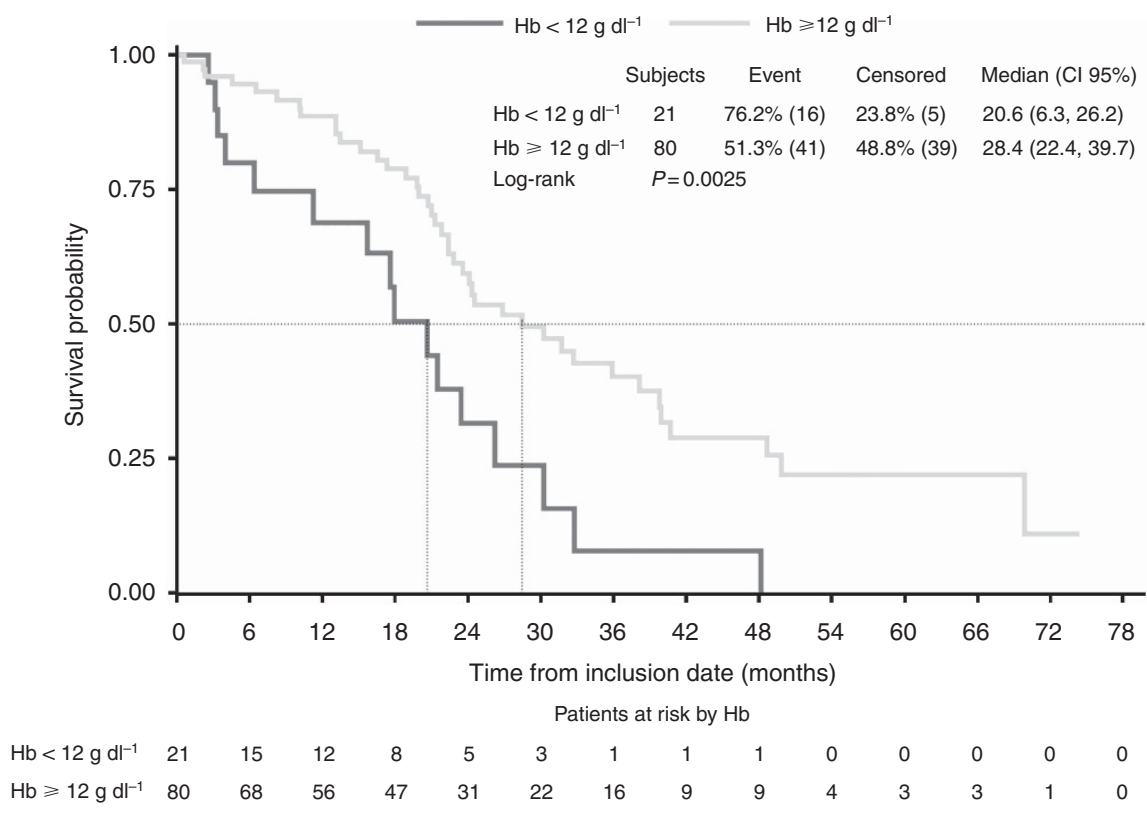

B Overall survival $(<65 / \geqslant 65$ years $)$

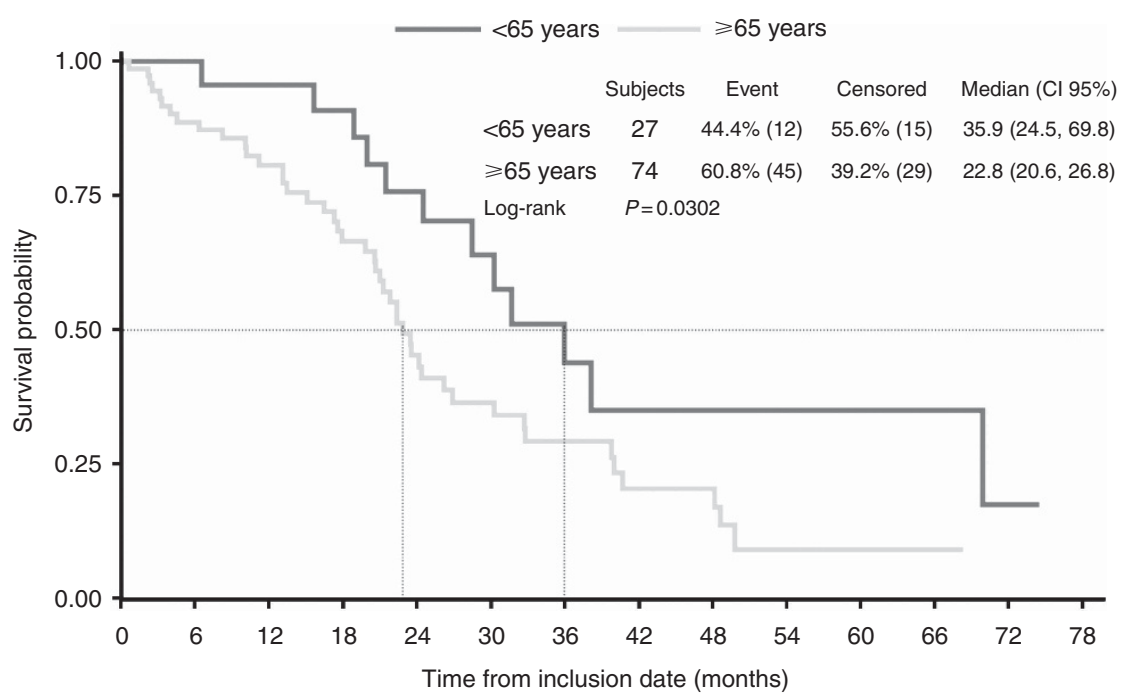

Patients at risk by $\mathrm{Hb}$

$\begin{array}{cccccccccccccc}<65 \text { years } 27 & 23 & 20 & 19 & 14 & 10 & 6 & 4 & 4 & 4 & 2 & 2 & 1 & 0 \\ \geqslant 65 \text { years } 74 & 60 & 48 & 36 & 22 & 15 & 11 & 7 & 7 & 2 & 2 & 2 & 0 & 0\end{array}$

Figure 3. Overall survival according to the presence of anaemia (A) or age (B) at baseline.

who is in poor general health. We plan to validate our results using an external data set.

It is noteworthy, in the multivariate analysis, that the presence of anaemia was a significant prognostic factor for OS. This finding correlates with Armstrong nomograms (Armstrong et al, 2007). To be aged 65 years or more was a prognostic factor in the univariate analysis, but losses statistical significance when considered in the multivariate analysis. Prostate-specific antigen was also a significant factor for survival but could not be included in the multivariate analysis since it showed a strong correlation with anaemia in the Wilcoxon test.

Although the Gleason score $(>7 v s \leqslant 7)$ and the presence of hepatic metastases (Yes vs No.) showed a notable difference in survival times in our series, this difference was not statistically significant, so we can only conclude that there was a trend towards better prognosis for survival with a lower Gleason score and an absence of hepatic metastasis. Gleason score obtained by biopsy was allowed in our series, and this may reflect an under staging in some patients. High $\mathrm{LDH}$, visceral metastases, and hepatic metastases were present in a small number of patients $(n=3)$, therefore no conclusion can be drawn up to now.

In conclusion, high baseline TLs seem to be a prognostic factor before first-line CT, and a predictive factor of improved OS among patients receiving hormonal manoeuvres after docetaxel. Moreover, AR activity can be analysed through biopsies of the tumour, and easier ways to estimate the activity of the AR are presently lacking. The analysis of plasma TLs could, if validated in a confirmatory study, be useful for decision of therapy. 


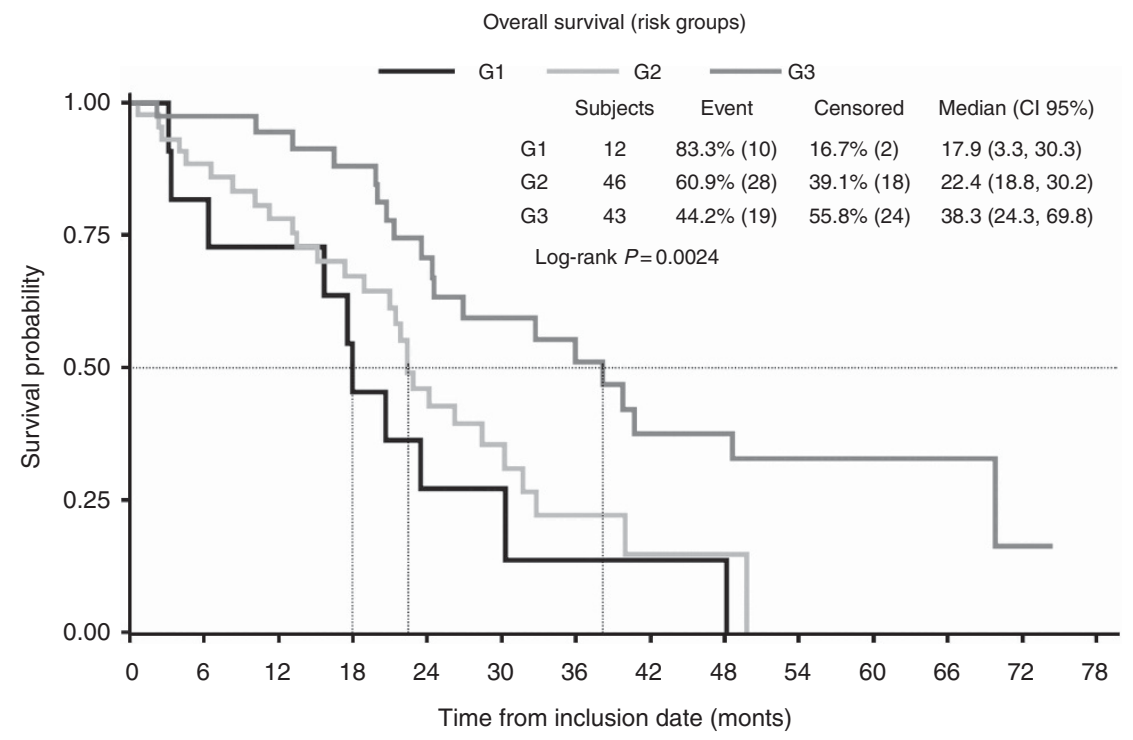

\begin{tabular}{|c|c|c|c|c|c|c|c|c|c|c|c|c|c|}
\hline & \multicolumn{13}{|c|}{ Patients at risk by group } \\
\hline G1 & 12 & 9 & 8 & 5 & 3 & 2 & 1 & 1 & 1 & 0 & 0 & 0 & 0 \\
\hline G2 & 46 & 37 & 30 & 24 & 14 & 8 & 4 & 1 & 1 & 0 & 0 & 0 & 0 \\
\hline G3 & 43 & 37 & 30 & 26 & 19 & 15 & 12 & 8 & 8 & 4 & 3 & 3 & 1 \\
\hline
\end{tabular}

G1: Patients with two risk factors (anaemia and testosterone $<11.5 \mathrm{ng} \mathrm{dl}^{-1}$ ), G2: Patients with one risk factor, G3: Patients without risk factors

Figure 4. Overall survival according to prognostic groups.

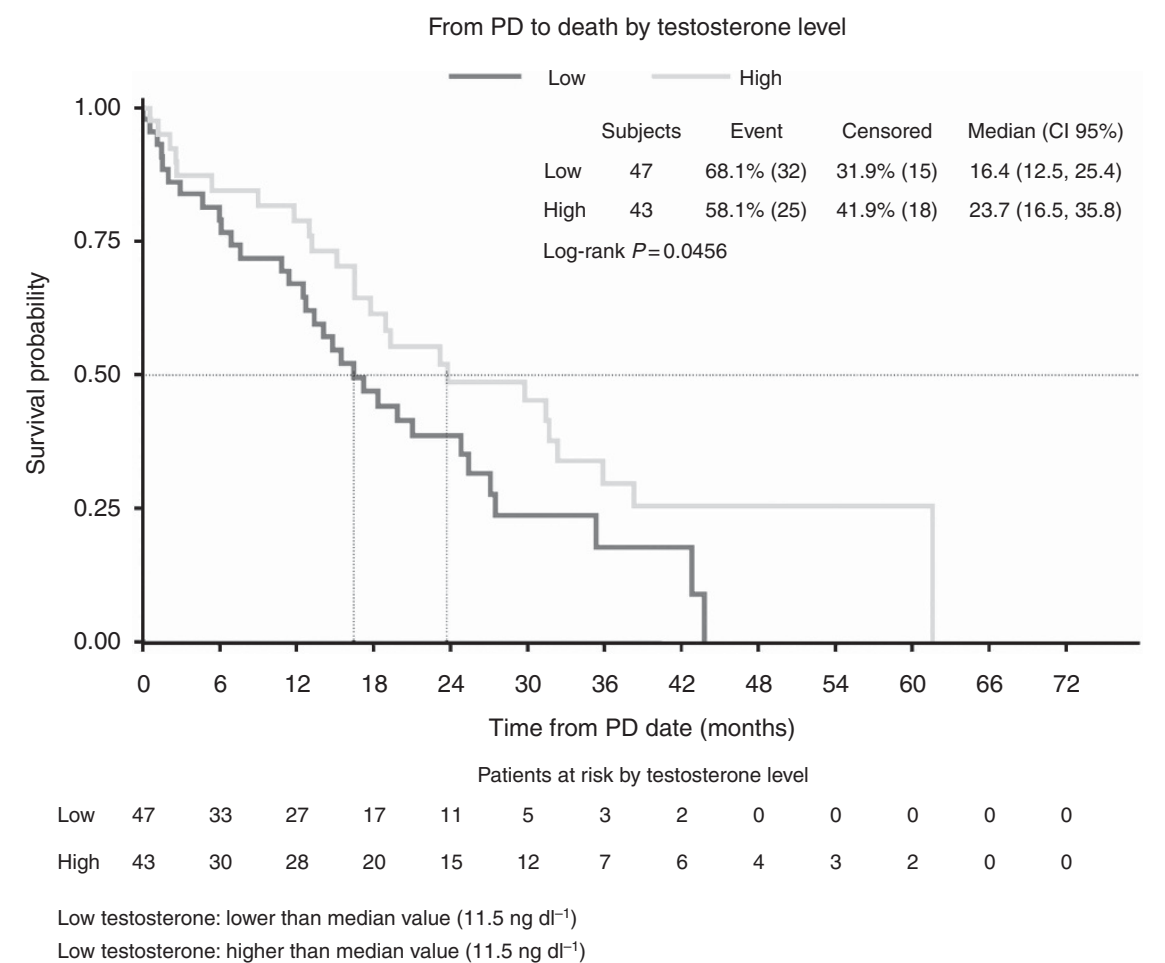

Figure 5. Time from progression to first-line therapy to death.

\section{ACKNOWLEDGEMENTS}

ClinicalTrials.gov identifiers: NCT00321620; NCT00744497; NCT01057810; NCT00411528; NCT00278993; NCT01308567; NCT00642018; NCT01188187; NCT00519285. This study was performed within the Medical PhD framework of A Gómez de Liaño at the Universitat Autónoma de Barcelona.

\section{REFERENCES}

Armstrong AJ, Garrett-Mayer ES, Yang YO, de Witt R, Tannock IF, Eisenberger M (2007) A contemporary prognostic nomogram for men with hormone-refractory metastatic prostate cancer: a TAX327 study analysis. Clin Cancer Res 13: 6396-6403.

Attard G, Reid AH, Yap TA, Raynaud F, Dowsett M, Settatree S, Barrett M, Parker C, Martins V, Folkerd E, Clark J, Cooper CS, 
Kaye SB, Dearnaley D, Lee G, de Bono JS (2008) Phase I clinical trial of a selective inhibitor of CYP17, abiraterone acetate, confirms that castrationresistant prostate cancer commonly remains hormone driven. J Clin Oncol 26: 4563-4571.

Darshan MS, Loftus MS, Thadani-Mulero M, Levy BP, Escuin D, Zhou XK, Gjyrezi A, Chanel-Vos C, Shen R, Tagawa ST, Bander NH, Nanus DM, Giannakakou P (2011) Taxane-induced blockade to nuclear accumulation of the androgen receptor predicts clinical responses in metastatic prostate cancer. Cancer Res 71(18): 6019-6029.

de Bono JS, Logothetis CJ, Molina A, Fizazi K, North S, Chu L, Chi KN, Jones RJ, Goodman Jr OB, Saad F, Staffurth JN, Mainwaring P, Harland S, Flaig TW, Hutson TE, Cheng T, Patterson H, Hainsworth JD, Ryan CJ, Sternberg CN, Ellard SL, Flechon A, Saleh M, Scholz M, Efstathiou E, Zivi A, Bianchini D, Loriot Y, Chieffo N, Kheoh T, Haqq CM, Scher HI (2011) Abiraterone and increased survival in metastatic prostate cancer. $N$ Engl J Med 364: 1995-2005.

de Bono JS, Oudard S, Ozguroglu M, Hansen S, Machiels JP, Kocak I, Gravis G, Bodrogi I, Mackenzie MJ, Shen L, Roessner M, Gupta S, Sartor AO (2010) Prednisone plus cabazitaxel or mitoxantrone for metastatic castration-resistant prostate cancer progressing after docetaxel treatment: a randomised open-label trial. Lancet 376: 1147-1154.

Efstathiou E, Titus M, Tsavachidou D, Tzelepi V, Wen S, Hoang A, Molina A, Chieffo N, Smith LA, Karlou M, Troncoso P, Logothetis CJ (2012) Effects of abiraterone acetate on androgen signaling in castrate-resistant prostate cancer in bone. J Clin Oncol 30: 637-643.

Eisenhauer EA, Therasse P, Bogaerts J, Schwartz LH, Sargent D, Ford R, Dancey J, Arbuck S, Gwyther S, Mooney M, Rubinstein L, Shankar L, Dodd L, Kaplan R, Lacombe D, Verweij J (2009) New response evaluation criteria in solid tumours: revised RECIST guideline (version 1.1). Eur J Cancer 45: 228-247.

Hashimoto K, Masumori N, Hashimoto J, Takayanagi A, Fukuta F, Tsukamoto T (2011) Serum testosterone level to predict the efficacy of sequential use of antiandrogens as second-line treatment following androgen deprivation monotherapy in patients with castration-resistant prostate cancer. Jpn J Clin Oncol 41: 405-410.

Locke JA, Guns ES, Lubik AA, Adomat HH, Hendy SC, Wood CA, Ettinger SL, Gleave ME, Nelson CC (2008) Androgen levels increase by intratumoral de novo steroidogenesis during progression of castrationresistant prostate cancer. Cancer Res 68: 6407-6415.

Loriot Y, Bianchini D, Ileana E, Sandhu S, Patrikidou A, Pezaro C, Albiges L, Attard G, Fizazi K, De Bono JS, Massard C (2013) Antitumour activity of abiraterone acetate against metastatic castration-resistant prostate cancer progressing after docetaxel and enzalutamide (MDV3100). Ann Oncol 24(7): 1807-1812.

McShane LM, Altman DG, Sauerbrei W, Taube SE, Gion M, Clark GM (2005) Reporting recommendations for tumor marker prognostic studies (REMARK). J Natl Cancer Inst 97(16): 1180-1184.

Mezynski J, Pezaro C, Bianchini D, Zivi A, Sandhu S, Thompson E, Hunt J, Sheridan E, Baikady B, Sarvadikar A, Maier G, Reid AH, Mulick CA, Olmos D, Attard G, de BJ (2012) Antitumour activity of docetaxel following treatment with the CYP17A1 inhibitor abiraterone: clinical evidence for cross-resistance? Ann Oncol 23: 2943-2947.
Montgomery RB, Mostaghel EA, Vessella R, Hess DL, Kalhorn TF, Higano CS, True LD, Nelson PS (2008) Maintenance of intratumoral androgens in metastatic prostate cancer: a mechanism for castration-resistant tumor growth. Cancer Res 68: 4447-4454.

Morote J, Orsola A, Planas J, Trilla E, Raventos CX, Cecchini L, Catalan R (2007) Redefining clinically significant castration levels in patients with prostate cancer receiving continuous androgen deprivation therapy. J Urol 178: 1290-1295.

Noonan KL, North S, Bitting RL, Armstrong AJ, Ellard SL, Chi KN (2013) Clinical activity of abiraterone acetate in patients with metastatic castration-resistant prostate cancer progressing after enzalutamide. Ann Oncol 24: 1802-1807.

Perachino M, Cavalli V, Bravi F (2010) Testosterone levels in patients with metastatic prostate cancer treated with luteinizing hormone-releasing hormone therapy: prognostic significance? BJU Int 105: 648-651.

Prevail Trial (2013) Medivation Press Release http://investors. medivation.com/releasedetail.cfm?ReleaseID=798880 (Last accessed on 13 December 2013).

Ryan CJ, Smith MR, de Bono JS, Molina A, Logothetis CJ, de SP, Fizazi K, Mainwaring P, Piulats JM, Ng S, Carles J, Mulders PF, Basch E, Small EJ, Saad F, Schrijvers D, Van PH, Mukherjee SD, Suttmann H, Gerritsen WR, Flaig TW, George DJ, Yu EY, Efstathiou E, Pantuck A, Winquist E, Higano CS, Taplin ME, Park Y, Kheoh T, Griffin T, Scher HI, Rathkopf DE (2013a) Abiraterone in metastatic prostate cancer without previous chemotherapy. $N$ Engl J Med 368: 138-148.

Ryan CJ, Molina A, Li J, Kheoh T, Small EJ, Haqq CM, Grant RP, de Bono JS, Scher HI (2013b) Serum androgens as prognostic biomarkers in castration-resistant prostate cancer: results from an analysis of a randomized phase III trial. J Clin Oncol 31: 2791-2798.

Scher HI, Halabi S, Tannock I, Morris M, Sternberg CN, Carducci MA, Eisenberger MA, Higano C, Bubley GJ, Dreicer R, Petrylak D, Kantoff P, Basch E, Kelly WK, Figg WD, Small EJ, Beer TM, Wilding G, Martin A, Hussain M (2008) Design and end points of clinical trials for patients with progressive prostate cancer and castrate levels of testosterone: recommendations of the Prostate Cancer Clinical Trials Working Group. J Clin Oncol 26: 1148-1159.

Scher HI, Fizazi K, Saad F, Taplin ME, Sternberg CN, Miller K, de WR, Mulders P, Chi KN, Shore ND, Armstrong AJ, Flaig TW, Flechon A, Mainwaring P, Fleming M, Hainsworth JD, Hirmand M, Selby B, Seely L, de Bono JS (2012) Increased survival with enzalutamide in prostate cancer after chemotherapy. N Engl J Med 367: 1187-1197.

Small EJ, Halabi S, Dawson NA, Stadler WM, Rini BI, Picus J, Gable P, Torti FM, Kaplan E, Vogelzang NJ (2004) Antiandrogen withdrawal alone or in combination with ketoconazole in androgen-independent prostate cancer patients: a phase III trial (CALGB 9583). J Clin Oncol 22: $1025-1033$.

This work is published under the standard license to publish agreement. After 12 months the work will become freely available and the license terms will switch to a Creative Commons AttributionNonCommercial-Share Alike 3.0 Unported License. 